\title{
1. On the particular challenges of managing professionals
}

\section{Flemming Poulfelt ${ }^{1}$}

We need to allow intelligent people to have freedom to think, while also recognizing that education's social role requires organization and management. (An anonymous academic: professor and former associate dean, 2015)

\section{INTRODUCTION}

Management and leadership together make up an interesting discipline. Running or orchestrating an organization in a smart way, to make it innovative, productive, effective, and attractive, has always been on the agenda for businesses and in the public sector. Principles around how to manage and lead have been proposed in thousands of textbooks and articles. Some of these are quite specific, directed at particular industries or vertical sectors; some toward certain kinds of organization; and others are geared to the different levels of management (e.g. directors, middle managers). For the purposes of this chapter, we will focus on approaches to leading or managing professionals, with an emphasis on the academic world.

\section{THE PARTICULAR CHALLENGE OF MANAGING PROFESSIONALS: REALITY OR MYTH?}

It is accepted wisdom in leadership circles, and particularly in academia, that 'professionals' are impossible to manage, and/or that they don't like to be led. The rationale is that these are people who are likely to have sizeable egos; who consider themselves masters of their domain. They believe they know the right way to go about things, and what not to do - without being instructed or guided. In an article published some years ago, managing professionals was likened to 'herding cats' (McKenna \& Riskin, 1995). As cats are thought to be highly independent, generally suiting themselves, the simile would appear perfect.

In an article appearing in Harvard Business Review (written by two London Business School professors) about the particular challenges of attempting to lead intelligent people, the authors note a characteristic resistance to suggestion, or to perceived interference. "If clever people have one defining characteristic, it is that they do not want to be led," the authors note. "This clearly creates a problem for you as a leader," they warn (Goffee \& Jones, 2007). From the TV or theater actor who behaves like a prima donna, to the lawyer who is certain of the truth in court, to the university professor with their already confident assessment, it can be difficult to influence these individuals' perspective or to encourage them to entertain alternative thinking or ways of behaving. They can seem defiantly and belligerently set in their ways. 
In addition, professionals often expect to be involved in and give an opinion on everything. I recall the case of a law firm where the consensus was that the partners 'always knew best' even down to the right color for the office curtains.

With so much anecdotal evidence to draw on, could it be that there is something about professionals that makes them fundamentally more difficult to lead or manage, or is this a self-perpetuating myth?

As it turns out there is considerable evidence to support the view that professionals expect to be left to manage themselves and decide what is right (self-management). But it is possible too that some bias has crept in along the way, and that this perspective may have been exaggerated. With this in mind, it feels appropriate to dig a little deeper. For instance, there is also considerable anecdotal evidence - from both the corporate world and across the academic domain - to suggest that many professionals do actually want to be led. The determining factor seems to be how.

Professionals' willingness to be led appears closely linked to the type of management and leadership they are exposed to. If there is a chance this will be 'wrong,' 'bad,' 'weak,' or 'incompetent,' professionals are more likely to be resistant. Unfortunately, responsible management has too often been found to be lacking in many professional organizations, both private and public. Maister (1994) suggests that, typically, "professional service firms have been managed in one or two ways: badly or not at all." Having worked with professional organizations (including consulting firms, law firms, and engineering firms), I readily concur.

More recent studies and analyses show that well-educated people would often welcome more management - with the caveat that those providing it are suitably qualified. In the corporate world there is a saying that "people leave managers, not companies," which highlights the critical role played by good management; and conversely the risk of poor or absent management or leadership.

In the academic world in particular, McCormack, Propper and Smith (2014) support this view in the context of managing researchers. They note: "Our results ... point to the important aspects of good management in the use of incentives ... to motivate academics. This contrasts with the commonly-held view that these individuals are impervious to good (or bad) management."

The point being made is that successfully managing professionals requires leaders that are capable of setting the direction, orchestrating the people and the organization, and driving strong performance. And it turns out that this is less about micro-managing these highly skilled people, and more about giving them the direction, freedom, and support to excel.

Jetley (2016) writes: "Manage less. The more you manage professionals, the more they will resist. Let them sweat it out. If they need help, they will ask. If they are really overworked, they will tell you. If they need reassurance, they will seek it." Jetley goes on to use a judo metaphor, urging leaders to harness the strength of the professionals rather than trying to fight it. "If you do this well, they will make all the effort and you will bask in the glory of the results they achieve," he writes, adding the disclaimer, "But do not expect any gratitude from them. They will still think of you as the chief clerk."

It seems quite incredible that universities function as well as they do when so few researchers have formal competency in leadership and management. It could be argued that if the same were true in a private company, in most markets that business would struggle to develop the competitiveness needed to survive and prosper. While academics leaders tend to be passionate 
professionally, most are happy/lucky amateurs in management, having limited formal skills and no actual leadership training to draw on.

\section{THE VIRTUES OF ACADEMIC LEADERSHIP?}

There is no doubt that managing academics is a challenging proposition, given the typical characteristics of high professionalism; a passion for their work; self-reliance; assuredness of their worth; and a low boredom threshold. In addition, Goffee and Jones (2007) argue that these knowledgeable individuals "won't thank you." "Even when you're leading them well, clever people will be unwilling to recognize your leadership," they note, adding: "Remember, these creative individuals feel that they don't need to be led. Measure your success by your ability on the fringes of their radar."

Many academics would admit to being self-centered, considering 'What's in it for me?' if asked to participate in a specific project or to contribute to a task. An important element of academic leadership, then, is the ability to read and understand researchers and what drives them. Empathy and understanding are critical tools in managing these professionals.

Of course, most managers in universities are academics themselves and have been (and perhaps are still) active researchers. This is typically true of presidents, deans, heads of department, and study board directors. And sharing that background provides important insight into those they must now lead, as well as bringing credibility to the role. As Sveiby and Lloyd (1987) argue, "It is impossible to lead professionals without being professional yourself." Assumed within this view is the primus inter pares (first among equals) perspective: that a leader of professionals must earn their spurs. For Sveiby, a worthy leader "is all but a patriarch." This manifests as "a creator of the work environment and a tutor, who creates opportunities for his employees"; someone who "channels intellectual energy, maintains a clear sense of direction and is the guarantor of continuity and security in [the] organization."

Whether it is definitively the case that the leader of professional teams must be an old hand at the given discipline is up for debate, since effective leadership comes down to how an individual exercises their role. But of course, having proven research credentials can be helpful in winning over larger egos.

In their book Aligning the Stars (2002), Lorsch and Tierney argue that outstanding leaders in professional service organizations aren't necessarily "the smartest, nor the most successful, nor the most experienced in their firm." Rather, what characterizes these individuals is "who they are as human beings," the authors note, adding that character, judgement, and intuition are common traits; that and their ability to exercise influence rather than control.

Set against this context, I will now share some of my own observations about what constitutes good leadership in an academic environment, based on my own studies and experiences. These are summarized below as a series of eight 'leadership virtues' I have identified.

\section{Setting the Direction}

One of the key tasks of a leader is to direct the future development of the organization. For, as the Cheshire Cat in Lewis Carroll's Alice in Wonderland points out, "If you don't know where you are going, any road will take you there." For obvious reasons, employees within an organization need to know where they are going, which means that someone - the leader - must 
define that destination. With the pace of change accelerating all the time, leaders must also be able to review and reconfirm the roadmap over time, to ensure that employees know how they can contribute to getting to the target end point and what their performance achievements should be along the way.

The long-term perspective or strategy is today well-anchored within most universities and departments. This is inevitable as universities must think ahead to set priorities and plan resources. The strategy will also inform stakeholders about how the institution will contribute to society going forward.

Defining the organization's path will usually involve defining (or redefining) the institution's purpose and vision, as well as the priorities around achieving these ambitions. Effective leaders will need to develop a clear vision of where they want to go; be able to describe this future in simple language; and provide meaningful guidance about how to move forward. In most academic environments this should not be a lone exercise; rather, it should serve as a way to engage and secure the commitment of researchers to a shared course.

"Nothing makes professionals more cynical than a manager who is weak, uncertain and lacking direction," writes the leadership author Jo Owen. "But once you have set the direction and goals, do not micro-manage," he warns. "Be firm on the goals, flexible on the route they use to get there ... let their professional pride and paranoia motivate them to achieve the outcome" (Owen, 2009).

\section{LEADING BY EXAMPLE?}

It is often argued that strategies are too ambitious, too ambiguous, or too complex, and therefore difficult to communicate. In contrast, the strategy at a Scandinavian university some years ago was a good deal more focused. In addition to setting out a vision for the university, the strategy comprised three clear priorities for the institution. These were formulated in such a way that most researchers could readily recall them, and were able to map their work to these priorities. This in turn saw the strategy come alive and make sense for the majority of employees.

On the other hand, I have also experienced strategies that have been formulated primarily at the top of institutions, without being anchored in the wider organization. In such cases, the scope to use the university strategy as a relevant and valuable leadership vehicle will decrease; rather, strategy feels more like an ethereal aspiration to show off to those looking in from the outside.

\section{Making Meaningful Decisions}

Leadership involves making decisions. Good leaders understand and know how to balance reason with emotions, and how to make decisions meaningful. Making grounded decisions that make logical sense is important in academic environments. Without sound reasoning, it will be hard to win acceptance and commitment from researchers. Unfortunately, many academic leaders seem to confuse the right to make decisions (given their power) with making them legitimate and accepted. 


\section{LEADING BY EXAMPLE?}

Structural changes within the academic world are always tough because, generally, (too) many researchers have a say on the proposed changes. No wonder so many major reorganizations (e.g. department mergers; a new faculty structure; or a major educational reform) are subject to critique and resistance. Yet the scenarios inviting the most critical behavior tend to be those that are the least meaningful to researchers. That is, the 'narrative' behind the changes is insufficient, inviting dissent. If the structural changes were more clearly framed, backed by a meaningful and well-articulated rationale, they might be more palatable.

\section{Creating Continuous, Two-Way Communication}

In the academic world, communication - whether written or oral - is a vital part of what goes on in both teaching and research. It is equally critical in management. To be effective and to sustain trusted relationships, managers must ensure ongoing communication with all employees, from researchers to administrative personnel. There is a strong argument, when hiring a manager, that good communications skills should be sought as a high priority - not only to build trust, but also to enable influence/persuasion, allow clear assignment of responsibility, and motivate and provide support to teams.

Miller (2012), for example, argues that managers will typically spend $75 \%$ of their time on communication with their teams and others within the organization. Few would argue with this. Yet, still, in academic environments complaints are rife about the quality and frequency of management communication. It may come too late; lack precision; and/or involve too much talking and not enough listening. Leaders' communication styles matter greatly. McKenna and Riskin (1995) urge leaders to "crank up the communication effort," noting that, "We routinely underestimate the amount of communication necessary to make our efforts successful." Winston Churchill, former and acknowledged British Prime Minister once said, "the difference between mere management and leadership is communication," indicating that communication skills are at the heart of effective leadership.

The importance of truly listening should not be underestimated, as this is how leaders will understand the context and the individual needs they are working with. My own observation over the years has been that while many leaders - including consultants and academic managers - make very good listeners, this tends to be primarily to themselves.

\section{Securing Real Involvement}

Involving people more integrally in activities that affect them has long been part of the leader's toolbox, on the basis that this is likely to motivate people, giving them a sense of ownership of the outcome. This accepted wisdom has been exercised in most university environments. Yet, 'involving' people can also lead to dysfunction if the gestures of inclusion prove to be little more than lip-service, and if expectations are not clarified in advance. 


\section{LEADING BY EXAMPLE?}

A newly appointed president at a Scandinavian university launched a process for a new strategy. Various taskforces were formed, comprising 6-7 people (primarily researchers), to take on specific themes. Initially there was a lot of goodwill and engagement. The process was scheduled to last for 3-4 months, including a pit-stop with the top management and the taskforce chair. During the process a consultant (from one of the top consulting firms, working on a pro bono basis) was assigned to each group - even though the group could not readily see the benefit of this resource. At the end of the allotted period, the groups submitted their report to the president. A fortnight later all the groups were invited to a strategy seminar - at which, to the surprise of most people there, a new strategy for the university was unveiled! No discussion had ensued since the submission of reports and in fact very few from the groups attending were able to recognize their contribution in the presented material. A project originally intended to increase engagement ultimately had the opposite effect: a drop in morale and poor support for the eventual strategy.

The hard lesson is that if you are going to invite people to participate in a project, it is vital that the intentions are sincere and that the mandate and associated expectations are clear.

\section{Inspiring, Recognizing and Supporting Best Performance}

The ability to inspire is perceived to be among the most important leadership traits, as this infuses energy, passion, commitment, and connection to an organization's mission and vision. According to Garton (2017), "inspired employees are themselves far more productive and, in turn, inspire those around them to strive for greater heights." An inspiring leader believes in others and themselves. They have a personality which can create passion, optimism, and enthusiasm. They believe in the mantra: 'If you want to change the way of being, you have to change the way of doing.'

\section{LEADING BY EXAMPLE?}

The most inspiring leaders within universities, to my recollection, have always been those able to make speeches in a convincing, optimistic, and meaningful way with profound insights - typically spiced up using humor. At the same time these leaders were able to hold conversations face to face, creating energy, optimism and action.

In the academic world there is a tendency to underestimate the value of recognizing people for their achievements, whether these are big or small. Sometimes there seems to be an assumption that acknowledgment is not necessary; that being an academic itself is a gift and source of passion. I disagree. I believe that recognition is a very inexpensive way of incentivizing people and of motivating researchers. 


\section{LEADING BY EXAMPLE?}

During my time as vice-dean of research communication, I used to write thank-you notes to those researchers who voluntarily offered their involvement at a national event with the focus on disseminating research. What surprised me was the number of notes I received in return, commenting how good it had felt to be recognized. My conclusion was that this kind of acknowledgment is shown too seldom.

Leaders can afford to be generous with their recognition. As McKenna and Riskin (1995) put it, "If you can't find something to recognize on a daily basis, you don't know how to look."

The importance of showing acknowledgment and appreciation cannot be understated. "Like world-class athletes, professionals have an almost insatiable need to know how they are doing: the more able they are, the keener their need," write DeLong, Gabarro and Lees (2007). They continue: "One highly-regarded mentor in a law firm reflected, 'For some of my best performers, I have to tell them how well they are doing on Monday, and again on Thursday. No amount of feedback is enough.",

Certainly, management support is important to employees: and not just in words. Meaningful support in academia means enabling researchers to do - and to excel in - their job. When they fail to provide this, managers inadvertently signal a lack of support. Demonstrations of support can take other forms too. It might be caring for a post-graduate student who is struggling to finalize his/her Ph.D. project. It could be supporting a research application for funding, or the initiation of a new research project. A colleague of mine once introduced the concept of 'management by mothering' as part of her leadership role, emphasizing the value of nurturing people as they grow. After all, the most important resources universities possess are their people - so why wouldn't an institution and its leaders do everything it takes to help them flourish?

\section{LEADING BY EXAMPLE?}

A president at a Scandinavian university took the view that good research initiatives should always be supported - as long as they were exceptionally good. This mindset encouraged innovation among the institution's researchers, inspiring new research initiatives. If someone had a solid idea and a strong outline they could approach the president for a meeting, always with the assurance that they would not have to wait for weeks. If their ideas were deemed to be sound and well-articulated, the researchers received support, often a small amount of seed money too - with the expectation that the individual would seek additional funding externally. It was common for people to leave these meetings feeling engaged, keen, and optimistic that research money would be found.

Another way of demonstrating managerial support is to shield researchers from 'organizational rain': that is, from the burden of policies and procedures imposed by the administration - so that researchers are able to concentrate on their principal tasks of research, education, and the dissemination of findings and knowledge. 


\section{Creating Engagement}

Leaders of today could be thought of as being in the human energy business. Extending the metaphor, it should be a priority for leaders to maximize the human 'wattage' they generate - and to ensure this is sustainable energy (that does not burn brightly, only to soon lose its spark). Put a different way, leaders need to be proactive and strategic in creating engagement and drive within the organization, bearing in mind that its most valuable resources are the people who work there.

Employee engagement is a subject Gallup has surveyed extensively over the years (Gallup, 2019). Its studies show that typically less than a third of all employees, worldwide, could be categorized as engaged. Gallup's findings also highlight the common drivers of engagement. One is that "people want purpose and meaning from their work ...; to be known for what they're good at." Academic environments have something of an advantage here, in that most researchers already attach meaning to their own work. However, they still need to feel part of an organization where engagement levels are high, and fuel everyday work.

\section{LEADING BY EXAMPLE?}

The question of what makes and keeps people engaged tends to be more involved than some leaders realize. Conversely, disengagement is achieved relatively easily. I have observed this first hand in research organizations where the role and behavior of the top manager has had a detrimental effect on researchers' morale. Even in universities where self-management and an inherent passion for people's own work are typically the norm, overall engagement levels can be damaged by poor decision-making - leading to disengagement, dissatisfaction, and discouragement.

\section{Promoting True Collaboration}

Analyses show that great leaders know the value of cooperation and how to collaborate effectively with colleagues and employees. Analyses also show that leaders who cooperate, share, and foster belonging will be more influential and successful over time. A willingness to cooperate includes sharing of information. Openness and transparency almost always pay off, although of course there will be some information that cannot be made public. When employees feel they are part of the network, and that they are 'seen' and appreciated, their sense of belonging and loyalty will be elevated.

Academics are used to cooperating as part of research projects and educational programs. However, their ability to foster a collaborative culture, and to truly engage people so that they feel they belong and want to give their all, may vary considerably. 


\section{LEADING BY EXAMPLE?}

On his appointment, a department head announced that one of his ambitions and personal strengths was creating a cooperative environment, which he believed gave rise to strong results. Both the researchers and the administrative staff were enthusiastic, sensing the dawning of a new era for the department. Others were more skeptical, having heard some rumors about their new leader's personality. Things started well but soon the spirit of cooperation morphed into a culture of order and control. This discrepancy between the promised culture and the reality created anger and frustration among the staff. The head had also begun to show favoritism toward certain researchers; a small group became so upset by this that they decided to leave the department.

It is one thing to talk the talk about establishing a collaborative culture, but if leaders promise one thing and deliver another, they have only themselves to blame if staff stage a mutiny! Another important point is that being a 'cooperative leader' should include being willing to share the 'spotlight.' Some leaders struggle with highlighting the work and achievements of others ahead of their own. But a smart leader recognizes that their power and status is best demonstrated by the success of those around them.

\section{LEADING BY EXAMPLE?}

As has already been noted, researchers have a reputation for being self-centered, unwilling to put themselves out for the wider cause unless they perceive that there is something in it for them (including glory). Some leaders exhibit these qualities too, putting themselves before their team and failing to acknowledge and hold up those who deserve honor and recognition. This type of leadership typically fails in the long run: employees soon realize that where they are soon singled out and criticized for any mistakes, they are not being given credit for their achievements.

\section{Executing According to the Plan}

For reasons that are self-explanatory, managers have a duty to get things done and to execute the strategy and plans of the organization. In practice, this can be difficult as daily operations get in the way. Yet, the value of any plan is in the ability to realize its ambitions. Ensuring that the organization 'lives' its strategy is a real leadership challenge, and a continuous one including efforts to support and follow up on the work, keeping everything on track. If there is a discrepancy between the actions and the perceived values of the stakeholders, execution can easily be shorted. 


\section{LEADING BY EXAMPLE?}

When I was a newly appointed leader of a research center serving four universities, I experienced the potential sensitivities of failing to consider other stakeholders sufficiently. The center had just been launched and we needed to advertise six positions for Ph.D. scholarships. All of the universities were involved and had contributed toward the wording for the advert, which I asked the HR department to place in a newspaper before the summer vacation. The ad appeared, large and prominent, in the Sunday issue of the biggest newspaper in the country. I was pleased with a job well done. But then trouble started. The HR people had used the format for ads at $m y$ university, showing only our logo. Although it was not my intention to exclude the branding of the other stakeholder institutions, some (a few) people were upset. Was this a kind of power-play; an indication of an uncooperative mindset, the other universities wondered. I was able to turn the situation around, but it was a stark reminder of how even small omissions can ruffle feathers and undermine harmony.

\section{ADDITIONAL REFLECTIONS}

In the introduction to this chapter, we have considered whether there might be something intrinsic to professionals that makes them fundamentally more difficult to lead or manage. The ensuing discussion and supporting evidence suggests that, contrary to the view that academic professionals are especially difficult to manage, the challenge is more specifically that they require a particular kind of management to bring out their best.

Leading or managing academics requires a careful blend of reason and emotion/the ability to 'read' the environment - as well as mindfulness that researchers are human beings with their own ambitions, needs, and expectations. Handling the subtle personal variances in personalities and expectations requires discernment and thought: there are no out-of-the-box solutions.

The eight 'leadership virtues' I have distilled above are based on leadership theory supported by my own observations from more than four decades of experience (on both sides of the desk) of academic leadership practice.

In summary, these can be boiled down to three primary recommended leadership behaviors:

- Ensuring that giving meaning to and making logical sense of strategies, plans, and requests is a priority;

- Inspiring, energizing, engaging, and supporting all human resources so people feel and give their best; and

- Ensuring that decisions and decision-making take place in this context.

I'll end with some refreshing advice proposed in a recent book (Leadership in Higher Education, 2019) by Kouzes and Posner - both very experienced leadership authorities. "Decide to do something different that will make you an even better leader," they propose. "Then hop off the log and get into the water!" The point being that it is only through our action that we are able to improve, learn, and perform. 


\section{NOTE}

1. Disclaimer: The title of the chapter refers to management rather than leadership, which is not intended to confuse the reader. Of course, 'management' and 'leadership' can have different connotations in business literature. 'Management' tends to be characterized as the 'hard (and dull) part' while 'leadership' is more 'soft (and creative)'. Some will argue that management is about administration, planning, organizing, performance, and control while leadership is about developing the vision, inspiring and engaging people, coaching, communication, and trust. As former President Dwight Eisenhower said, "Leadership is the art of getting someone else to do something you want done because he wants to do it."

While the distinction is important, I would argue that a successful leader/manager will combine and balance the two sets of qualities. A 'boss' (perceived negatively) is likely to have placed too much emphasis on the management part, where a more liberal leader may not always achieve results in the most effective way, it could be argued. Both of these standpoints are open to debate. In this chapter, the use of the terms leader and manager are applied with an element of discretion.

\section{REFERENCES}

DeLong, T.J., Gabarro, J.J. \& Lees, R.J. (2007). When Professionals Have to Lead. Harvard Business School Press.

Gallup (2019). http://www.gallup.com.

Garton, E. (2017). How to be an inspiring leader. Harvard Business Review. April 25.

Goffee, R. \& Jones, G. (2007). Leading clever people. Harvard Business Review. March 2007.

Jetley, V. (2016). What's the main obstacle in managing professionals? https:/www.bayt.com/.

Kouzes, J.M. \& Posner, B.Z. (2019). Leadership in Higher Education. Berrett-Koehler Publishers.

Lorsch, J.W. \& Tierney, T.J. (2002). Aligning the Stars: How to Succeed when Professionals Drive Results. Harvard Business School Press.

Maister, D. (1994). Managing the Professional Service Firm. The Free Press.

McCormack, J., Propper, C. \& Smith, S. (2014). Herding cats? Management and university performance. The Economic Journal. August.

McKenna, P.J. \& Riskin, G.A. (1995). Herding Cats. The Edge Group.

Miller, P. (2012). Leadership communication - the three levels. Today's Manager, Singapore Institute of Management. Issue February-March.

Owen, J. (2009). 5 ground rules for managing professionals. CBSNews.

Sveiby, K.-E. \& Lloyd, T. (1987). Managing Knowhow: Add Value by Valuing Creativity. Bloomsbury. 